Daniela Corina lonescu*

Faculty of Foreign Languages and Literatures

University of Bucharest

Romania

\title{
A CONTRASTIVE ANALYSIS OF FOOD IDIOMS: LINGUISTIC AND CULTURAL PERSPECTIVES
}

\begin{abstract}
This paper will attempt to pinpoint the basic linguistic and cultural characteristics of food idioms in English and Romanian. A cognitive and lexical-syntactic analysis evinces certain structures which can be tested cross-linguistically. Food idioms are analyzed contrastively, in terms of their transparency/opacity gradient, starting from their lexical-semantic composition and syntactic flexibility, i.e. the possibilities of the given phrase to undergo nominal modification, substitution, passivization, aspectuality, negative formation, etc. In conceptual terms, any such pair will also include an 'image-trigger', which gives rise to a metaphor or a metonymic reading, therefore to a figurative, idiomatic interpretation, by projecting the literal to the meta-literal or figurative language. This is the source of conceptual similarity or dissimilarity between the two languages, reflected in the contrasted idiomatic patterns.
\end{abstract}

Key words: figurative meaning, conceptual metaphor, image-trigger, idiomaticity, transparency vs. opacity

\section{Preliminary notes on the definition and scope of idiomaticity: a syntactic-lexical and conceptual view}

The analysis starts from a common assumption related to the structure of idioms, their non-compositionality, in terms of their categorial components, i.e. the sum total of the meanings of each syntactic phrase does not make up the meaning of the whole structure which constitutes the idiomatic, wholistic meaning.

This paper will attempt to pinpoint the basic linguistic and cultural characteristics of food idioms in English and Romanian. A cognitive and lexical-syntactic analysis evinces certain structures which can be tested cross-linguistically. For instance, the thematic relation holding between the lexical verb and its complement, a direct internal argument of the transitive verb, found within an idiomatic phrase is the source of both a lexical and a metaphorical relationship within the respective syntactic structure (V+internal argument), as in the examples below:

\footnotetext{
*Faculty of Foreign Languages and Literatures, English Department, 7-13 Pitar Mos, St., Sector 1, Postal Code 010451, Bucharest, Romania; e-mail: daniones@gmail.com; daniela.ionescu@lls.unibuc.ro
} 
(1) chew the fat, eat crow, spill the beans;

(2) Rom.: A mânca răbdări prăjite (to eat nothing), a lua caimacul (milk something for what it's worth), a vinde gogoși cuiva (tell sb lies).

Therefore, the dependency between the parts of an idiom is semantic in nature, hence, the idiomaticity of the phrase. If we analyse idioms syntactically, there will be a certain degree of "flexibility" that most, if not all of them could have; for instance, the presence of either the definite or zero article in the NP domain of objecthood, in transitive verb phrases: spill the beans, vs. *spill beans, or pull the strings, vs. *pull strings. Phrases with zero article are: eat humble pie, or eat crow. In these examples, the NP object functions as a mass, not as a count noun, as it acquires a figurative meaning ('humble pie' would refer figuratively to a certain way of acting, in a humble, self-victimizing way, and "crow" would have the same figurative interpretation, in "eat crow'). However, syntactic flexibility can vary and is mostly defined as permutability, or the way in which specific syntactic transformations are possible for a particular construction. If a transformation is possible, this is taken as evidence that the construction is syntactically flexible.

From a lexico-syntactic perspective, certain shifts are tested to focus on the question if material of any kind can be added (or omitted) without affecting the idiomatic interpretation of a phrase. For instance, the fact that *"He kicked the bucket slowly" or passive formation: *"The bucket was kicked" are instances of ill-formedness is evidence of the inflexibility or frozenness of this idiom. However, St. Wolff (2008: 5) comments that the variant: He kicked the bucket quickly is acceptable, but she offers no explanation as to its acceptability. It is, in fact, obvious that the lexical aspect of the verb "kick" (telic, achievement) somewhat coincides with the lexical meaning of the adverb "quickly". Therefore, there is no semantic incompatibility between the verb and the adverb in the quoted alternative idiomatic sentence.

Apart from passivization and (non)definiteness, the third syntactic test for idiomatic flexibility (and compositionality) is modification, within a VP phrase, where the nominal phrase is modified by some adjective, as in the famous: leave no [legal] stone unturned, or have a [nice] [tiny] bun in the oven.

Ellipsis and emphasis through topicalization are also used to evince syntactic "flexibility":

My goose is cooked, but yours isn't. (quoted in Nunberg et al. 1994: 501).

This feature can be applied cross-linguistically, for instance:

(a) Those strings, he wouldn't pull for you.

(b) Rom. Sforile nu le trage el, ci ea. (The strings, it isn't him, it is she who pulls them). 
In Romanian, the idiomatic phrase "a trage sforile" has the same figurative meaning as the English "pull the strings".

At this point, we can resume the definition of an idiomatic phrase, given by Nunberg et al. (1994), so as to further try and identify the main features of idiomaticity in a phrase: "An idiomatic phrase is ... an idiosyncratic type of phrasal construction that is assigned its own idiomatic meaning". "...Idiomatically combining expressions ... consist of a fundamentally semantic (typically figurative) dependency among distinct lexemes, however restricted in distribution these lexemes might be". (cf. Nunberg et al. 1994: 507).

A central feature of the analysis focuses on the semantic dependency of verbs and their objects, for instance, the object "the beans" is unable to occur with any verb other than spill so as to be interpreted as 'revealing a secret'. But the literal meaning of spilling the beans is necessary, in some circumstances, so as to acquire a metaphorical or figurative meaning in the idiomatic sense and be re-interpreted at this level (reveal a secret).

Nunberg et al. (1994) claim that idioms are situational metaphors and they try to demonstrate this view in their extensive article, by underlining the semantic impact of the combining idiomatic expressions both on the sentence where they occur and on the phrasal interpretation per se. In this sense, the phrase "spill the beans" has both a literal and a figurative meaning. The NP "the beans" has no ability to occur with any other lexical verb, except "to spill", in its idiomatic mapping. The meaning of this verb phrase is conventionally and homomorphically associated with the idea of unveiling some secret. This dependency among the parts of the expression is "fundamentally semantic in nature" (cf. Nunberg et al. 1994: 505). For instance, the phrase chew the cud is interpreted literally to mean "ruminate"; figuratively, it means "to think with great care". This metaphoric (figurative) phrase has its roots in the conceptual metaphor of the reversibility of food - thought, i.e. a thought goes to and fro like the ingested food. The root metaphor is "Thought is food" (of the brain). However, in syntactic terms, the idiom above is a VP: [chew - the cud]. The figurative, metaphorical nucleus lies in the lexical verb "to chew".

As Nunberg et al. note that there is a tendency of metaphorical mappings that goes from concrete to abstract and that can be illustrated in phrasal idioms of different syntactic types, such as: a high frequency of [+animate] lexical VP, where the lexical verb implies an animate reference within its meaning, e.g.: kiss the canvas, cook someone's goose, put all one's ducks in a row, get someone's goat, kill the goose that lay the golden eggs, lock the stable (barn) door after the horse has bolted, look a gift horse in its mouth, back the wrong horse, place, one's head in the lion's mouth, keep the wolf from the door, etc. (Nunberg et al. 1994: 528). 
These idiom chunks, according to Nunberg, have idiomatic meanings that apply either exclusively to inanimates or to both inanimates and animates. However, the inanimacy of the direct object NP is a characteristic that is met cross-linguistically, and it can be explained through the tendency of such phrases to acquire a metaphorical reading in discourse.

According to Nunberg et el. (1994: 529), this sort of (metaphorical) transfer is caused by the proverbial feature of idiom chunks: "a proverb or proverbial expression invokes a concrete situation (pulling the strings, showing the flag, break the ice, put all one's eggs in one basket, etc.) as the metaphorical model for a recurrent, culturally significant situation involving abstract relations or entities (e.g. exerting influence, making one's opinions known, risking everything at one go, etc.).

Concluding at this point on the concrete and transfer-to-abstract reference in idiom chunks on account of their metaphorical transferability, I am re-iterating the general view on the syntactic and semantic characterization of idioms, to some extent, in keeping with Nunberg et al. (1994) and with Everaert's more recent work (2010): the conventionality ('fixedness') and non-compositionality principles of idiom chunks have led many linguists to overlooking the fact that the meanings of most idioms do have identifiable parts, i.e. they imply an inherent motivation of idiomatic usage, from a semantic and pragmatic perspective. If there are certain asymmetries in the grammatical or thematic roles of idiom chunks, we should not interpret these asymmetries too "narrowly", because they are the consequence of a broader tendency in the figurative use of language.

This tendency is widely analyzed nowadays within the field of cognitive conceptual studies, by Fillmore, Goldberg, and others within the frame and construction theory about language and idioms within language use.

Concluding on the nature of compositionality of idioms, Nunberg et al. (1994) gave a sort of inclusive answer in that they consider that not syntax is called upon to solve the problem of (non)compositionality of idioms. Rather, they found an answer in the semantic features of the idioms, in the way in which they can actually be described.

First, idioms are conventionalized, i.e. their meaning and use cannot be predicted; they are used in a context and it is from context that they extract their meaning, according to the knowledge of the users (speakers and listeners alike, ideally) about the world, culture, traditions, presuppositions, life experience, etc. Conventionality must be understood properly, in the sense that it does not mean conforming to something that is not known or understood by the user beforehand. It implies a relationship between some linguistic irregularity, a situation of use, and a population or group of people who have implicitly agreed to conform to that regularity in a certain situation out of a preference for general uniformity, not for any other compelling reason to conform to that regularity (D. Lewis 1969, apud Nunberg et al. 1994). 
The second trait of idiomaticity is inflexibility, according to which idioms typically appear only in a limited number of syntactic frames or constructions, unlike freely composed expressions. For instance, a phrase such as "shoot the breeze" cannot vary formally into: *shoot one breeze, or shoot the *same breeze", although there are many other phrases that are subject to syntactic variation, e.g. "leave no [proverbial] stone unturned", where the additional modifier is acceptable, with the lexical and traditional ironic allusion.

Figuration is the third semantic feature shared by idioms, i.e. idioms typically involve metaphors, metonymies, hyperboles, or other tropes. In what follows, in this chapter, we shall tackle figuration and figurative language in general, from the perspective of conceptual metaphor. In fact, we shall see that a metaphor contributes to the outlining of several potential conceptual mappings, which constitute the referential frames of idioms and their primary domains from which they transfer the meaning into a secondary or target domain, through a conceptual representation of the respective experience or factual event.

Proverbiality is the fourth feature, by means of which idioms typically describe and explain a recurrent situation of a particular interest (either social or individual, psychological). Informality is a property of idioms that locates the idiom in a specific register, usually, of an oral or colloquial colour.

\subsection{Gradients of transparency/opacity - idioms' syntactic flexibility}

Judging on the degree of idiom transparency (or opacity gradient) helps us interpret the meaning and figurative interpretation of idioms in a more efficient manner in general and of the food idioms in particular. For instance, if we use the tests for their syntactic flexibility on a par with contrastive analysis between English and Romanian food idioms, by way of e.g. passivization, aspectuality, nominal modification, negative formation or substitution, the constrastive "pairs" of English and Romanian food idioms will lead us to an interesting overview of their metaphorical and conceptual similarities or differences.

In conceptual terms, any such pair will also include an 'image-trigger', which gives rise to a metaphor or a metonymic reading, therefore, to a figurative, idiomatic interpretation, by projecting the literal to the meta-literal or figurative language. This is the source of conceptual similarity or dissimilarity between the two languages, reflected in the contrasted idiomatic patterns. Ultimately, it is at this level that cultural, pragmatic differences or common features become apparent. It is by way of this characterization that idiomatic conceptual maps can be constructed, so as to prove instrumental in establishing contrastive stereotypes, whether cultural or linguistic, or both, with regard to food items (listed in equivalent pairs). 
The analysis of food idioms can be outlined as a set of four different stages:

- Stage 1: formal degree of transparency/opacity (lexical-syntactic), which is based on the continuity constraint on idioms, the head-to-head 'chain' relationships that hold the idiomatic phrase together and give it internal unity and structure.

- Stage 2: conceptual metaphor/metonymy - base figurativeness (through CITconceptual integration theory);

- Stage 3: Contrastiveness of image-triggers in the creation of 'images' in the conceptual process of idiom production and comprehension in the two contrasted languages and cultures;

- Stage 4: Equivalence-based synoptic view of the lexical-syntactic encoding of the idiomatic construction: cultural relevance and form, and blending perspectives.

While applying this four-stage analysis to a limited set of idioms and proverbs in English and Romanian, by the end of the analysis, we expect it to evince the basic structural, conceptual differences and common features with regard to food items (listed in equivalent pairs or binominal idiomatic sets), in terms of frequency and lexicalization of certain cultural concepts, such as: bread, a certain type of vegetables, common to the temperate climate, e.g. onion, garlic, tomatoes, potatoes, etc., certain food items related to meat or to dairy products: cheese, eggs, milk. Wine as a product of entertainment, conviviality, and good life is also looked at contrastively, in the bi-lingual (binominal) idioms. Certain structural and lexical, as well as semantic regularities, are obvious in a variety of idiomatic patterns below.

\subsection{Constraints on idiomatic formation: continuity, hierarchy and selection in the validation of idioms}

Even though idioms need not form constituents, O'Grady (1998) contends that they are subject to an important grammatical constraint. The key to formulating this constraint lies in the relation that holds between heads and their dependents - i.e., their arguments, modifiers, and specifiers, including determiners in the case of nouns. The intuition is that a head licenses its dependents in that its syntactic and semantic properties determine the number and/or type or other elements with which it can or must occur (e.g. verbs take one or more nominal arguments and allow appropriate adverbial modifiers, nouns allow particular determiners and adjectival modifiers and so on). In accordance with Chomsky (1993: 6), a lexical item licenses its dependents via the heads and a clear example is provided by subcategorization.

Extending an idea put forward by Baltin (1989: 6), O’Grady (1998: 283) further assumes that licensing is a head-to-head relation, i.e. "a lexical item licenses its 
dependents via their heads". As Baltin notes (Baltin 1989: 5, apud O'Grady 1998), it does not suffice to stipulate that verbs such as declare and wait select CP complements: as the following examples show, the former verb requires a CP headed by that and the latter - a CP headed by for (for a comparable example involving PPs, see Jackendoff 1990: 256). Baltin suggests that the subcategorization frames for declare and wait should include the information in the frame below, with the verb selecting only the head of its complement phrase:

(4) declare, $\mathrm{V},{ }_{\mathrm{C}}$ that $]$; wait, $\mathrm{V},{ }_{-} \mathrm{C}_{\mathrm{C}}$ for $]$.

The verb in the phrase open the door very slowly licenses door (the head of its object argument) and slowly (the manner adverb heading the modifier phrase). These elements in turn license dependents of their own - a determiner in the case of the noun and a degree word in the case of the adverb. In dependency grammar terms, we can represent this aspect of a phrase's organization as follows, with an arrow indicating a licensing relation, as above; in this way, we can represent the VP:

(1) open the door very slowly

(2) open the door very slowly

Drawing on the notion 'chain', O'Grady (1998) formulates the following grammatical constraint on idioms:

(3) The Continuity Constraint: An idiom's component parts must form a chain.

On this view, the most basic idioms are expressions such as see stars and lose face, which consist of a verb and the head of its theme complement (stars and face, respectively).

Out of the VP-based idioms, the dyadic verbs (verb-theme) frequently evince a certain degree of semantic opacity (e.g. kick the bucket, bite the dust, shoot the breeze, chew the fat, etc.). O'Grady's basic assumption is that idioms form chains of headto-head relationships which represent a selection of both a lexical and an idiomatic nature. In fact, we must view selection from a dual perspective, in this connection. Even if neither Bruening (2010) nor Osborne et al. (2011), lately, have identified a special kind of idiomatic selection, different from the lexical or functional one, I maintain that in the case of idioms whose structures can be represented in a phrasal or in a dependency grammar model are connected by a typical relation, which is based on phrase structure rules (such as categorial or semantic). However, the respective selection of a noun as an argument of a V or of a preposition or of a modifier of a noun or an adjunct to the adverb, etc. is dictated by some figurative or conceptual associations which are concept- or culture-bound.

Therefore, a dual sort of analysis would be necessary for a better comprehension of idiomatic production in a language: a. syntactic and lexical-conceptual (i.e. synchronic) and b. cultural (i.e. diachronic). In this chapter, a brief analysis will be 
provided for a limited set of food idioms, cross-linguistically, so as to propose a working syntactic and semantic analysis which can be further refined and enriched. Along this line, O'Grady stresses the fact that the creation of idioms involves two parallel mechanisms - one grammatical and the other - semantic. However, what he really means by "semantic" is in fact the figurative meaning, however, this interpretation is still based on the semantic conceptual selection rule:

"Idioms are formed when a particular chain of heads takes on a figurative sense, creating a form-meaning pair that speakers feel is worth preserving in the lexicon of their language." (O'Grady 1998: 289).

Therefore, grammatical theory can account for the internal organization of the form of an idiom, but has nothing to say about the figurative meanings and cognitiveculture-bound associations that are assigned to that form.

The Continuity Constraint, as well as the Hierarchy Constraint, account for the succession of arguments. The linearity and asymmetry theory regarding ditransitives is also a rule that proves useful in the analysis of idiomatic phrases with dyadic predicates (ditransitives in double object constructions, e.g.: give $\mathrm{x}$ the cold shoulder, where the $\mathrm{V}+$ Theme argument constitutes the idiomatic constraint, while the Goal argument is 'free' idiomatically). Below I quote the hierarchy constraint, as discussed by O'Grady (1998: 293):

(4)"Any arguments that are part of a verbal idiom must be lower on the hierarchy than arguments that are not part of the idiom".

What this constraint predicts is that verbs of the $<$ th, loc $>$ and $<$ th, goal $>$ type should appear in idioms that include the goal or location argument, while excluding the theme, because the Theme argument is external to the predication. Therefore, the most prominent argument, i.e. the subject is not expected to occur in an idiom, while the theme and the goal, in a ditransitive predication, where the external argument is an Agent, ought to occur in the idiom, or if the subject is the Theme argument, then the goal or locative should occur as complements of the verb in a sentential idiom. Finally, triadic verbs of the <ag, th, goal/loc $>$ type are expected to occur in idioms that include just the Goal/Location argument or both this argument and the Theme. This general typology will be illustrated and discussed in the analysis section below.

Within the present lexical-semantic and syntactic analysis of idioms and proverbs, I take them to be constructions (i.e. conventional 'units') that consist of a conventional pairing of form and function, or that have a form-meaning correspondence that exists independently of a particular verb or of any other lexical item and is not strictly predictable from its component parts or from other constructions recognized to exist. According to A. Goldberg (2005), idioms form a conceptual networking (a 
syntax-lexicon continuum, in construction grammar theory). However, they cannot be considered as 'given' within the Lexicon taxonomies, since the selection relation determines choice of arguments for a lexical head such as a verb or a noun or an adjective, etc.

Selection of these arguments by the dominating lexical category is the basic principle of idiomatic interpretation. Structurally, idioms are limited either to a VP (most commonly) or to a variety of phrase types, according to the governing lexical category, such as: AP, PP, NP, AvP, or an IP (sentential idiom).

The apparently feasible theory of idiom formation relates to the systematic aspect of idioms (M. McGinnis 2002), their conceptual or dependency networking (in construction grammar terms), the continuity constraints (O'Grady 1998) and chain formation theory (as a head-to-hear relation), etc. Then, apart from the verb in $\mathrm{V}+\mathrm{Ob}$ constructions, where either or both of the lexical categories is constrained, in terms of 'continuity' (and head-to-head relation principle), there are many idioms which also contain prepositions, which prove equally constrained, as shown above. Prepositions are heads of the PP within the idiom structure, as in: "the ceiling caved in on John [when he saw her]" (cf. O'Grady 1998 (41a): 298). In this example, the preposition "on" is the head of the Loc. Argument (John), a nominal head of the PP, licensed by the lexical verb+(incorporated/conflated) Prt [cave in].

A related problem comes from the fact - also noted by Nunberg et al. (1994: 500) - that parts of idioms can take non-idiomatic modifiers, e.g. kick the filthy habit, pull yet more strings, leave no legal stone unturned, etc. The presence of an NP-internal modifier in these patterns 'interrupts' the idiom, preventing the mapping of its component parts onto any independently motivated constituent. This syntactic flexibility of idioms, by means of which non-idiomatic elements are inter-relating with idiomatic parts shows which part is fixed or frozen, lexically speaking, and which parts are flexible, in syntactic terms. For instance, out of the VP-based idioms, the dyadic verbs (verb-theme) frequently evince a certain degree of semantic opacity (e.g. kick the bucket, bite the dust, shoot the breeze, chew the fat, etc.).

\section{Argument structure and constraining hierarchy in idioms}

The infrequency and semantic transparency of idioms that violate the Hierarchy Constraint suggests that argument structure is relevant to idioms, albeit in a way that is not fully understood, and that there is a strong tendency for idioms built around dyadic verbs to include arguments from the lower part of the hierarchy. As we will see in the next section, idioms formed from triadic verbs exhibit similar properties. Bruening (2010) outlines the syntactic behaviour of triadic verbs (in ditransitive constructions of 
the Double object type), and further refines the theory of idiom formation in minimalist terms, by claiming that an asymmetric relation characterizes ditransitive as well as transitive verb-based idioms.

The Continuity Constraint accounts for different types of permissible constructions and this also predicts which idioms are impossible. Furthermore, we will investigate if and how the Hierarchy Constraint allows to rule out impossible argument structures of verbs. The preliminary assumption is that the syntactic structure of Romanian (food) idioms resembles that of the English examples. Idiomatic constructions of both languages are subject to similar syntactic constraints which limit their creativity. The Continuity Constraint seems to apply in nearly all cases.

Both constraints seem to make predictions regarding the selection of arguments within an idiom scope. This propensity of idioms to be argument-dependent derives from the core of syntactic and semantic rules, i.e. selectional restrictions and subcategorization frames. For instance, with dyadic verbs, the prediction is that the Agent, i.e. the most prominent argument, will be excluded from an idiom structure, whereas the theme argument - as a lower argument within the VP, is present in a variety of idioms: rock the boat, hit the road, settle the score, pop the question, kick the bucket, take the cake, win the battle, do the honors, bite the dust, lift a finger, smell a rat, save the day, etc. (cf. O'Grady 1998: 295). There are also many idioms that consist of a verb and a locative or goal argument to the exclusion of the agent, e.g.: grasp/ clutch at straws, start from scratch, skate on thin ice, come to the point, swim against the current, beat around the bush, etc.

With triadic verbs, according to the $\mathrm{HC}$, where the regular thematic structure is: $<$ ag, theme, go/loc $>$, the verb forms an idiom with its goal or location argument but not with its theme argument. As regards prepositional dative/locative constructions and double object constructions, it is the verb and its goal argument that forms an idiom, not the theme.

On the other hand, exclusion of the Theme argument, placed in a canonically external nominative assigning position of an unaccusative construction is a constraint that holds cross-linguistically, for instance, in Romanian, in an idiom like: $a-i$ cădea cu tronc fata/băiatul/rochia/melodia...[+/-human] (= to fall for someone: a girl, a boy, a dress, some song...), the Dative argument (Experiencer), the prepositional phrase, where "tronc" is a noun marked for case by the governing preposition is selected idiomatically, the externalized Theme argument is freely selected lexically, therefore, it is excluded from the idiom (cf. O'Grady's examples, 1998: 300).

A duce pe cineva cu zăhărelul is a Romanian idiom, meaning: to tell lies to sb, trying to misguide someone intentionally (lit. meaning: lead sb ahead with a lump of sugar). The PP [cu zăhărelul] is an Instrumental argument, idiomatically selected, 
while the Theme is free. The continuity constraint holds between the verb a duce and the PP cu zăhărelul or cu vorba, both PPs being headed by the same preposition CU, which determines the choice of an Instrumental argument of the predicate.

According to O'Grady, the creation of an idiom involves two parallel mechanisms - one grammatical and the other - semantic: "In particular, idioms are formed when a particular chain of heads takes on a figurative sense, creating a form-meaning pair that speakers feel is worth preserving in the lexicon of the language". (O'Grady 1998: 289).

Even if grammatical theory has nothing to say about why particular meanings tend to extend figuratively or why some figures of speech are more readily chosen than others, the continuity and the hierarchy constraints play an important role in describing the internal organization of the forms (idiomatic forms) that can be assigned figurative meanings in a given language. For instance, if we take a Romanian idiom, such as " $a$ inșira gogoși" (tell lies, exaggerate and falsify events, states of affairs), the head would be the verb (a inșira=literal: lay (beads, etc.) on a string, one-by-one; fig. tell, say, keep saying) and the phrase [a înșira gogoși] would be a transitive structure with a direct internal argument, Theme (gogoși). The label after merging of the two concatenated elements, the verb and the noun - argument of the verb, is a verbal phrase, determined by its lexical head, the verb. The idiomatic interpretation derives from the figurative meaning of the internal argument "gogoși", which is a food item, unlikely to be set on a string. Hence, the idiomatic meaning of telling lies, one after the other, in a given communicative context.

\subsection{Idiomatic mappings in the context of cognitive and cultural linguistics}

Cognitive Linguistics is a maximalist approach in the sense that it aims to account for real language in use in all its complex glory. It is a socio-cognitive and cultural framework in which lexical meanings are inextricably associated with language users' bodily, perceptual and cognitive experiences of cultural and historical phenomena. Our use of words is constrained as well as promoted by subjective and intersubjective conditions in the act of social communication. There is no strict dichotomy between linguistic and encyclopaedic meanings (Paradis 2003). Rather, lexical meaning in Cognitive Linguistics is encyclopaedic, i.e. it takes into account any aspect of contextual meaning modulation that is relevant for a certain research task, integrating semantics, pragmatics, and grammar in general (Paradis 2012).

In the Cognitive Linguistics framework, there is a direct mapping of words and expressions to conceptual structure. The function of words is to evoke conceptual patterns in the cognitive system. Speakers and hearers are intentional creatures. The way we express ourselves is functionally motivated; we wish to get our message through 
to our interlocutors and to negotiate meanings in communication with other people in an optimally successful way. There are no stable word meanings, rather meanings of words are dynamic, context-sensitive and construed during and on account of effective communication. Language is a conceptually structured inventory of linguistic units which are used in a conventionalized way according to different situations. Multiple meanings of words are expected as a natural consequence of a dynamic, usage-based view of language. The dynamics of language, its change in meaning and sometimes in form is due to cultural schemas that emerge from interactions between the members of a cultural community. What is significant in the acquisition, comprehension and usage of idioms is that they are part of the inventory of the macro level of communication which develop during the constant interactions between the members of a cultural group, on the basis of collective memory. However, idioms are individually perceived as part of the 'narrow' lexicon, which encodes pragmatic and sociolinguistic information (cf. Everaert 2010: 96).

The idioms also encode exceptional properties, linguistic and/or socio-cultural, this being the reason why they are so idiosyncratic in terms of form and meaning alike. We could follow Sharifian's theory of cultural schemas by considering idioms to manifest at the "micro level", where each individual acquires and internalizes the macro level schemas (related to customs, socio-cultural patterns (see Sharifian 2011: 478). Idioms are both collective (as part of the macro level of the language inventory) and idiosyncratic (at the micro level of the individual use of language), hence they can be distributed in a highly individualized perception while still preserving the typology of the macro level of a given cultural schema.

For instance, if we are to analyse the cultural schema of the following Romanian idiomatic phrases: a fi iute ca ardeiul (lit.tr. be as hot as a hot pepper), a fi dulce ca mierea (li.tr. be as sweet as honey), a pescui in ape tulburi (li.tr. fish in murky/troubled waters), a se îmbăta cu apă rece (get drunk with cold water), a bate apa în piuă (pestle water in a mortar) - on the one hand and the English ones: be about as useful as a chocolate pot, be in apple pie order, butter wouldn't melt in their mouth, cooking with gas, (for all) the tea in China, or be as cool as a cucumber - on the other hand - we can illustrate the differently distributed macro and micro levels of cultural schemas in the two languages, cross-linguistically.

In the cross-linguistic and cross-cultural analysis below, there is a list of Romanian idioms that have been selected from the Food scenario, in both languages. As expected, a common core does exist in the encyclopedic inventory, to be related to the vital elements of nutrition, which are category-based, such as: water, bread, milk, fish, meat, poultry or beef, mutton or pork, vegetables, the most common of which are: onion, garlic, tomato, potato, cucumber, or fruits: apples, pears, prunes (plums), 
cherries; household 'tools', used in preparing food: spoon, knife, oven, etc. and the derived ingredients for preparing food stuff: flour, eggs, cheese, butter, oil, lard/bacon, spices (pepper, salt, etc.).

Basically, the current nominal lexical inventory includes vegetables, grains, meat, game, cattle and poultry, as well as predicate-based cooking activities such as: boil, broil, sieve, steam, stew, bake, crust, crunch, crack, cut, etc. The properties are also classifiable into categories such as: done, underdone, overdone, boiled, hot (hot potato), red (red herring), big (big cheese), dry, roast (Dry bread at home is better than roast meat abroad), etc. As expected, the correlative idiom or saying or just 'literal' interpretation of the original food-denoting idiom is not a food-denoting expression. The idiomatic meaning is evocative of some cognitive, metaphorical association based on the speaker's encyclopedic and cultural knowledge. For instance, the idea of uselessness in action is rendered through a food-idiom (as useful as a chocolate teapot, while in Romanian this idea is idiomatically expressed by a body-related expression (see the equivalent idiom below). What is constant, nevertheless, is the explicit cultural comparison in both languages.

It is, therefore, relevant to discuss both English and Romanian food-related figurative language with their correlative figurativeness into the target languages, i.e. Romanian and English respectively. The common as well as the different figurative domains of relations encoded in idiomatic expressions may reveal interesting cultural, folk and historical or social conclusions, starting from two different linguistic idiomatic patterns, and practically revealing the true nature of semantic and linguistic motivation.

In heuristic terms, sampling the two corpora would lead to a better understanding of the use of certain idioms, even nowadays, or, on the contrary, of the non-use and gradual depreciation of collective memory as regards many others.

For instance, the idiom "Nici usturoi n-a mâncat, nici gura nu-i miroase" (lit. tr. = neither did he eat garlic nor does he smell of it, i.e. butter would not melt in his mouth, meaning to pretend being innocent) is almost "forgotten", as it does not 'say' too much to a young, computer-user or to the majority of people who are no longer great consumers of garlic. On the contrary, an idiom such as "a încasat o fäineală" (meaning "he was reprimanded", he was scolded) or "a fi mare legumă", lit.tr. "be a big vegetable" (i.e. be a big boss/shot, have financial and political power) are current idioms in colloquial or everyday speech.

Below is a short list of the common food lexical items to be met in idiomatic language, cross-linguistically. We can also call these items common cultural stereotypes and metaphors/metonymies, as they contribute to the understanding and contrastive analysis of the two idiomatic inventories, English and Romanian:

- Onion - no value, hence: both in English and in Romanian idioms; 
- Fish - essential in English culture, ubiquitous (common to English and Romanian);

- Bone - indicative of lack of substance, by semantic extension, lack of richness, state of poverty and deprivation (e.g. bone of contention = Rom. collocation: cuiul lui Pepelea (i.e. Pepelea's nail, ad litteram), focal point of dispute between two or several people; both phrases are noun-headed, they are nominal phrases, despite their totally different cultural and semantic significances); Romanian idiom: a fi numai piele și os (be only skin and bone, i.e. be very thin, very weak too);

- Bread-and-salt: Romanian stereotype (showing hospitality, if you welcome someone with bread and salt);

- Bread-and-butter: English stereotype (butter, not present in Romanian idioms; butter is considered to show some upper social status in Romanian culture); "unt si miere": butter and honey - have a certain kind of wealth or show some kind of hypocrisy: a fi numai unt si miere;

- Wine - an aphrodisiac and 'tranquilizer' - common stereotype (Rom. and English);

- Meat and sweets - indicative of richness and substance, in general: common stereotype;

- Spilt milk, spilt liquid: unnecessary regrets - common stereotype;

- Egg - present in metaphorical and metonymic idioms, being indicative of immediate advantages, lack of risks, profit - a cultural feature specific in the English idioms, which is absent in Romanian idiomaticity.

- Cheese - good life, good quality - common stereotype, but with specific semantic features in each language;

- Swine - animal perceived as a sign of dirt and rough sort of life, uneducated, unrefined, gross behavior; common stereotype; nu mânca din troacă pt. că te mănâncă porcii! (don't eat with the swine from the same tray, as they are going to eat you, meaning, to not associate with swine, they will finally eat you up); English idiom: cast pearls to swine (in Romanian: a strica orzul pe gaste: lit.tr. "waste oats on geese");

- Wheat/cereals in general - sign of hard labour and moral reward - common stereotype.

One final note must be mentioned in relation to the individual analysis of the selected idioms below: the linguistic and cultural equivalence is established on the basis of the literal (dictionary-based), explanatory meaning of the idioms, in both languages. Hence, there may be distinct semantic frames or even scenarios, conceptual 
schemata, categories and metaphors that the respective idioms evoke, in each language. Sometimes, they coincide, they are identical, or they are formulated on the basis of the same lexical-semantic pattern.

\section{Image-triggering phrases and proverbs - contrastively}

Each time, a sort of Image-trigger lexical 'unit' is identified within the lexical structure of the idiom, as a metaphorical, associative "trigger" of the whole semantic (sub)frame, thus projecting the lexical unit to a target, secondary conceptual domain. This cognitive trigger derives from the primary domain by way of mental processes of cognition, recognition, association and blending/production. The image-trigger word (or lexical unit) also determines the "theme" or thematic frame of the idiom and it is the main determining factor in lexicographic idiomatic dictionaries and specialized glossaries, therefore, it is most useful, from the linguistic but also from the cognitive and cultural points of view.

Below are two samples of English and Romanian samples of food idioms and proverbs which are roughly described and analysed in conceptual, lexical, and grammatical terms. They are listed under A and B samples, respectively, according to their semantic label, which is noted between square brackets. Cultural comparison and linguistic contrastiveness is the primordial effect of the analysis:

\section{1. [INEFFICIENCY IN ACTION; USELESSNESS]; IRREVERSIBILITY OF ACTS PERFORMED}

\section{Image-trigger lexical 'unit'/word: chocolate-pot}

- About as useful as a chocolate teapot $=$ Someone or something that is of no practical use is about as useful as a chocolate teapot

\section{Variants:}

- As much use as a chocolate fire-guard = A fire-guard is used in front of a fireplace for safety. A chocolate fire-guard is of no use. An alternative to 'As much use as a chocolate teapot'.

- As much use as a chocolate teapot $=$ not useful at all

Romanian equivalent: este ca o frecție la un picior de lemn $=$ Lit. translation = 'it is as useful as a massage in a wooden leg' - image-trigger word: picior-delemn: wooden leg

\section{Analysis:}

[be] as useful as a chocolate teapot: copular idiomatic expression, the predicative is simile-based, a comparative structure, the comparative functor which 'flanks' the adjective useful, the lexical concept which triggers of the metaphor of the chocolate 
teapot. A sort of "mathematical" riddle, which equates usefulness with a tool that is logically and culturally considered to be of no urgent use, thus triggering invalidation of the affirmative structure. The Romanian expression: este ca o frecție la un picior de lemn is also based on a comparative construction, by the presence of the comparative particle CA and the nominal "o frectie"+Locative phrase "la un picior de lemn" see literal translation above). The Locative is an entrenched lexical concept which triggers off the comparison to something completely useless or invalid, therefore, the interpretation is uselessness of a certain state of affairs or facts. The semantic chain or linking relation holds between the noun "frectie" and the Locative phrase "la un picior" [de lemn]. It is the chain between the noun "picior" and its nominal modifier "de lemn" that is idiomatic, since a treatment - if any - is supposed to be applied to a living part of the human body. The idiomatic selectional chain is quite long with this expression, because we first have a selection of a locative phrase "la un picior" by the head noun "frectiie", then - a selection of the PP "de lemn" by the head the noun "picior", and both selections form the whole phrase, as above, alluding to the uselessness of the attempt.

\section{Image-trigger lexical 'unit'/word: Barn; milk:}

- Don't shut the barn door after the horse is stolen. (Rec. dist. U.S., Can. $1^{\text {st }}$ cit. approx.. 1350, Douce MS 52, ed. Forster, Erlangen 1906 - proverb

\section{Image trigger/lexical unit/word: cry, milk}

- Don't cry over spilt milk = When something bad happens and nothing can be done to help it people say, 'Don't cry over spilt milk'. - proverb

Romanian equivalents: Degeaba plângi că ți-a dat păsatul în foc=You cry for nothing now that polenta failed boiling// Acum degeaba plângi pentru laptele vărsat =It's useless to cry over spilt milk; or: Image-triggers: păsat; lapte; război, viteji (polenta, milk, war, brave men)

Image-trigger lexical unit/word: egg, boil

You cannot unboil an egg - proverb

Romanian equivalent: Ce se face nu se mai desface, Lit. Tr. What is done cannot be undone

Analysis: Proverb 3 above is an advisory negative sentence with an adverbial temporal clause specifying the useless action of closing a barn door after the horse has already been stolen, after the damage is done. It indirectly invites to caution and good farm and house management. It is not necessarily related to food, but it is based on the same metaphor of uselessness of an action because of lack of caution. Proverb no. 4 is related to spilled milk and the useless action of crying over it. Therefore, the same metaphor is implied, while invoking a different image. It also occurs in the form of a negative imperative sentence, as a leading precept of life. 
The Romanian equivalent (It is no use crying for unboiled polenta/for the fact that maize has been all boiled into the fire, and nothing is left in the boiling pot) evokes a different image, related to the habit of cooking polenta, according to the very simple recipe, whereby the housewife pours corn flower into the boiling water and keeps stirring until the corn flower thickens and turns into the traditional "mămăliga" or polenta, while obviously, water level in the pot, while boiling continuously, decreases gradually. The structure is a complex one, including a main clause and an adverbial, causative clause, governed by the complementizer CA/that (ți-a dat păsatul în foc). Proverb 4 is a very poignant way of expressing the unnecessary, post-hoc intervention, which cannot repair a harm already done. Romanian has got a similar way of expressing the same idea (also in a proverbial form), but it is a generic, more abstract one: Literally: "whatever has been done cannot be undone" (ce se face nu se mai desface).

Analysis of the phrase "don't cry over spilt milk": idiomatic expression, a VP, where the verb is unergative and it selects a PP, which describes the cause of the event of crying: over spilt milk. This is a PP, where the preposition selects the NP with a modifier (spilt), selected by the noun: milk. The idiomatic meaning derives from the incongruent action of crying for something that cannot be recuperated. Both the continuity and the hierarchy constraints apply in this case, since the verb, which is a monadic verb selects an indirect argument which in its turn is selected by the preposition "over".

\section{2. [IDENTICAL, NEAR-IDENTICAL OR SIMILAR PHYSICAL APPEARANCE AND/OR BEHAVIORAL FEATURES]: SIMILE}

Image-trigger Lexical Unit/word: two peas

- Alike as two peas (in a pod) = If people or things are as alike as two peas, they are identical

Rom. equivalent 1: Sunt ca două boabe într-o păstaie,

Rom. equivalent 2: S-au găsit tusea cu junghiul...=They found each other: cough and stitch/twinge together

Analysis: Perfectly motivated simile. Syntactically and lexically, it is based on a comparative structure (alike as...), where the similarity between two people is compared to that of two peas of the same kind and aspect (to be found in a pod), inducing identity of individuals, with respect to physical and behavioral features. The copulative BE is the head of the predicative SC [IP they I'BE SC [ $t$ - alike] PrtP [as two peas] (in a pod)]. 
3. SELF-SUSTAINABILITY AND LUCIDITY (No exaggerations); BALANCE in one's state of wealth

Image-trigger/lexical unit/word: barns, pull down

- Do not pull down your barns to build bigger ones. (Rec. dist. Kans., N.Y.; proverb (Biblical origin: Luke, 12:18).

Approx. Rom. equivalent: $\mathrm{Nu}$ da vrabia din mână pe cioara de pe gard $=$ Lit. translation: Do not give the sparrow in your hand for the crow on the fence (idm. A bird in the hand is worth two in the bush)? A se imbăta cu apă rece... (a nutri iluzii deșarte, a crede în ceva imposibil, greu de realizat)

Analysis: This proverb, in the form of a negative restrictive type of sentence evokes the advice of restraining to what someone can afford, financially and maybe physically too, in terms of physical force, strength to do something. It is selfexplanatory and it can be used metaphorically, to suggest balance and caution in one's effort of doing something. The syntactic structure is that of a negative sentence, where the adverbial final clause is in the infinitive, with an implicit PRO subject, referring to the addressee. The Romanian approximate equivalent has a similar structure, but it is not complex, it includes a single sentence (the main clause), with a direct and an indirect prepositional object (pe cea ...), followed by a nominal modifier (de pe gard). Again, the English perfect version is listed above (a bird in the hand...), which is almost identical in terms of lexical conceptualization, excepting the place where the bird not in someone's hand may be: not on the fence, but in the bush.

\section{Conclusions: food idioms within the language-and-cognition framework; the cultural food metaphor}

Like any other lexical item with a cognitive description (e.g. love, hate, life, death), for which a conceptual metaphor is made available, food can also be conceptualized metaphorically, by following Lakoff's theory of conceptual metaphor, which evolved so productively in many other theories of language and cognition together. H. G. Wolf and F. Polzenhagen (2007) quote Lakoff's remarks on the identification of several metaphors associated with food and eating habits. (Lakoff 1993, online).

The food metaphors constitute cultural conceptual associations in the language: (especially in the media). They are most salient, conceptually, as they are linked with a vital source of human existence, both in the material and the 'immaterial' world. On the other hand, lack or scarcity of food, famine, deprivation, undernourishment also generate a whole range of linguistic and cultural associations: strong desires are conceptualized as Hunger; Resources are conceptualized as food (resources are food); Achieving is conceptualized as eating, yielding achieving a purpose is eating; 
"Being important is having achieved" is conceptualized as being big, physically, as a result of eating: being important is being big; Not needing something anymore is conceptualized as not wanting enough (of something); acquiring knowledge is eating/ digesting and giving information is feeding, e.g.: She devoured the book. The teacher spoon-fed them the material. This lecture is hard to digest (cf. Wolf and Polzhagen 2007: 409-412).

All the above metaphors form a kind of conceptual chain or network, being based on the key metaphor of "acquiring knowledge is eating". This specific metaphor network in the field of information and ideas is common to all varieties of English, but it is predominant in the IT language and in the political press. In Romania, for instance, especially on the eve of general (parliamentary) elections, one of the popular commentaries that appeared in the press was related to the "national cake" (the original: "tortul national"), or "sarmale electorale", "cîrnați electorali" (electoral traditional dish, "sarmale", electoral sausages, etc.). These are phrases (ad-hoc collocations) that imply both a metaphor and a concrete (ironical) reference to festivities organized for the people, in an attempt to manipulate the mass in favour of some political party.

Depending on the cultural context, metaphors may occur in isolation or as an entire conceptual network. (cf. Wolf and Polzhagen 2007). For instance, the well-known metaphor: FOOD means intellectual/mental source of knowledge (give someone food for thought, give someone information to think about, to process, etc.). e.g. This is a very meaty book (ibidem). In Romanian, although rarely, can we come across such expressions as: a (se) hrăni cu cărti, cu informații etc. (feed on books, information, news). In press, the colloquial phrase: "Ce-mi dai/aduci azi?" - Lit.tr. = What do you give me today, what have you brought me?, i.e. "Any news, What news have you got?"). Therefore, the metaphor: HUNGER FOR KNOWLEDGE is quite common, cross-linguistically (Fr. Avoir une soif d'apprendre plus; Sp. Sed de conocer mas, English: appetite for learning more) In Romanian, as well as in other languages (French, Spanish, English), the idiomatic phrase metaphorizing sb.'s yearning for learning more also comes as "thirst": o sete de cunoaștere (Lit. tr. thirst for knowledge): e.g. He has an appetite for learning/thirst for knowledge. She has an insatiable curiosity.

We can conclude the present paper by assuming that the most comprehensive view would be within the framework of cultural language and cognition. The schemas, categories and metaphors are conceptualizing instruments resulting from the interactions between the members of a cultural group (cf. Sharifian 2003).

According to the analysts of language as a cognitive cultural phenomenon, the "members of a cultural group may share some but not all elements of an emergent cultural schema with each other, and what is shared between two members may not be 
exactly the same as what is shared by two others in the group" (see more in Sharifian 2003).

Idioms and proverbs are examples of collective linguistic 'memory' entrenched in the context of physical experiences in various cultures and languages. As such, they operate like cognitive "anchors" for the users' conceptualizations; in our specific case Food is an anchor for the conceptualization of ingesting information, knowledge, and ultimately - wisdom. This anchor may be operational in several groups or several cultures and languages, hence a cross-linguistic comparison and contrast in this respect is most resourceful, both linguistically and culturally. Obviously, it is imperative to attach much more importance to this approach in further studies related to the production and significance of idioms in human languages and cultures. Enfield's or Sharifian's views on cultural linguistics are illustrative in this sense (cf. Enfield 2002, 2014; Sharifian 2003, 2011).

Idioms as fixed expressions of language are best accommodated within a schema-and-category-analysis, as they represent adaptive language systems of encapsulating what is valid within a cultural, cognitive, and linguistic group, so as to facilitate understanding springing from the interaction among the members of that (cultural and linguistic) group. This is the reason why in the future an interdisciplinary analysis - linguistic, cognitive, cultural - of idioms would ultimately prove to be more efficient and more resourceful in this new inter-disciplinary view.

\section{References}

Baltin, M. (1989). Heads and Projections. In: M. R. Baltin and A. S. Kroch, Alternative Conceptions of Phrase Structure, Chicago: The University of Chicago Press, $1-16$.

Bruening, B. (2015). Idioms, Anaphora and Movements Diagnostics. (27 November 2019) <https://udel.edu/ bruening/Downloads/IdiomsMovement2.pdf $>$.

Enfield, N. J. (2002). Introduction. In: N. J. Enfield (ed.), Ethnosyntax, Oxford: OUP, $3-31$.

Enfield, N. J. (2014). Natural Causes of Language and Frames, Biases, and Cultural Transmission. Berlin: Language Science Press.

Everaert, M. (2010). The Lexical Encoding of Idioms. In: M. Rappaport-Hovav, E. Dand and I. Sichel (eds.), Lexical Semantics, Syntax and Lexical Structure, Oxford: OUP, 76-97.

Goldberg, A. (2005). Verbs, Constructions, and Semantic Frames. In: M. RappaportHovav, E. Dand and I. Sichel (eds.), Lexical Semantics, Syntax and Lexical Structure, Oxford: OUP, 39-59. 
Jackendoff, R. (1990). Semantic Structures. Cambridge, MA: MIT Press.

Jackendoff, R. (1995b). The Boundaries of the Lexicon. In: M. Everaert, E-J. van der Linden, A. Schenk, R. Schreuder (eds.), Idioms: Structural and Psychological Perspectives, Hilldale, NJ: Lawrence Erlbaum, 133-165.

Horn, G. (2003). Idioms, Metaphors and Syntactic Mobility. Journal of Linguistics, 39, 2, July 2003, 245-273.

Ionescu, D. (2017). Food Idioms and Proverbs in English and Romanian - A Crosslinguistic and Cross-cultural Approach. Bucharest: OSCAR Print.

Lakoff, G. (2006). Conceptual Metaphor. In: D. Geeraerts, R. Dirven, J. Taylor (eds.), Cognitive Linguistics: Basic Readings, Berlin and New York: Mouton de Gruyter, 185-239.

Langlotz, A. (2006). Idiomatic Creativity. Amsterdam and Philadelphia: John Benjamins Publishing Company.

McGinnis, M. (2002). On the Systematic Aspect of Idioms. Linguistic Inquiry, 33/4, $665-672$.

Nunberg, G., I. Sag and T. Wasow (1994). Idioms. Language, 70, 3, Sep., 491-538.

O'Grady, W. (1998). The Syntax of Idioms. Natural Language and Linguistic Theory, 16(2), 279-312. doi: 10.1023/A:1005932710202

Paradis, C. (2003). Is the notion of linguistic competence relevant in Cognitive Linguistics? Annual Review of Cognitive Linguistics, 1, 247-271.

Paradis, C. (2012). Lexical Semantics. In: C. A. Chapelle (ed), The Encyclopedia of Applied Linguistics, Oxford: Blackwell, 3356-3357.

Sharifian, F. (2003). On cultural conceptualizations. Journal of Cognition and Culture, $3,187-207$.

Sharifian, F. (2011). Cultural conceptualisations and language: Theoretical framework and applications. Amsterdam and Philadelphia: J. Benjamins Publishing Company.

Wolf, H. G. and F. Polzenhagen (2007). Fixed expressions as manifestations of cultural conceptualizations: Examples from African varieties of English. In: P. Skandera (ed.), Phraseology and Culture in English, Topics in English Linguistics, Berlin and New York: Mouton de Gruyter, 399-435.

Wulff, S. (2008). Rethinking Idiomaticity - A Usage-based Approach. London and New York: Continuum. 